\title{
Comorbidities in chronic obstructive pulmonary disease: Results of a national multicenter research project
}

\author{
Renata Rubinsztajn ${ }^{1, A-F}$, Tadeusz Przybyłowski ${ }^{1, A-F}$, Marcin Grabicki, ${ }^{2, A, B, E}$, Krzysztof Karwat ${ }^{1, B, E}$, \\ Marta Maskey-Warzęchowska ${ }^{1, B, E}$, Halina Batura-Gabryel ${ }^{2, A, B, E, F}$, Ryszarda Chazan ${ }^{1, A, C-F}$ \\ ${ }^{1}$ Department of Internal Medicine, Pulmonary Diseases and Allergy, Medical University of Warsaw, Poland \\ ${ }^{2}$ Department of Pulmonology, Allergology and Respiratory Oncology, Poznan University of Medical Sciences, Poland \\ A - research concept and design; $\mathrm{B}$ - collection and/or assembly of data; $\mathrm{C}$ - data analysis and interpretation; \\ $\mathrm{D}$ - writing the article; $\mathrm{E}$ - critical revision of the article; $\mathrm{F}$ - final approval of the article
}

Address for correspondence

Renata Rubinsztajn

E-mail: rrubinsztajn@wum.edu.pl

\section{Funding sources}

The study was funded by National Center for Research and Development, Warszawa, Poland; project "Chronic obstructive pulmonary disease (COPD) - systemic disease, the biggest threat of the $25^{\text {st century" }}(13003406 / 2009)$.

\section{Conflict of interest}

None declared

\section{Acknowledgements}

We would like to thank Monika Kosacka MD, PhD, Barbara Mackiewicz MD, PhD, Grzegorz Gąsior MD, PhD, and Krzysztof Kędziora MD, PhD for their help in data collection.

Received on March 28, 2017

Reviewed on July 28, 2017

Accepted on September 26, 2017

Published online on August 29, 2018

\section{Cite as}

Rubinsztajn R, Przybyłowski T, Grabicki M, et al. Comorbidities in chronic obstructive pulmonary disease: Results of a national multicenter research project. Adv Clin Exp Med. 2019;28(3):319-324. doi:10.17219/acem/78024

DOI

10.17219/acem/78024

Copyright

Copyright by Author(s)

This is an article distributed under the terms of the Creative Commons Attribution Non-Commercial License (http://creativecommons.org/licenses/by-nc-nd/4.0/)

\begin{abstract}
Background. Chronic obstructive pulmonary disease (COPD) is associated with various comorbidities, which influence the course of COPD and worsen prognosis.

Objectives. The aim of this study was to analyze the comorbidities in a cohort of COPD patients in Poland during 12 months of observation.

Material and methods. A total of 444 COPD patients (median age: 66.1 years) in all stages of airflow limitation severity were enrolled. Medical histories and a questionnaire concerning comorbidities were analyzed at baseline and after 12 months (data of 267 patients available). Anthropometric data, pulmonary function, and body mass index, airflow obstruction, dyspnea, and exercise capacity (BODE index) were assessed.

Results. No comorbidities were reported in 9 patients (2.0\%), 101 patients (22.7\%) had 1-2 comorbidities, 243 (54.7\%) had 3-5, and 91 (20.6\%) had more than 5 comorbidities. Cardiovascular diseases (CVDs) were the most frequent ones, followed by peptic ulcer, obstructive sleep apnea (OSA), diabetes, gastroesophageal reflux disease (GERD), and osteoporosis; 11 patients had a history of lung cancer. Cachexia was observed in 11 cases, overweight in 136 cases and obesity in 139 cases. The incidence of CVDs increased with time. The number of comorbidities correlated with the body mass index (BMI) and the number of hospitalizations for extra-pulmonary causes, but not with airflow limitation. The BODE index score increased with the number of comorbidities.

Conclusions. In a cohort of Polish COPD patients, the most frequent comorbidities were CVDs. The number of comorbidities affected the BODE index, but not airflow limitation. The BODE index is better than forced expiratory volume in $1 \mathrm{~s}\left(\mathrm{FEV}_{1}\right)$ in the rating of COPD patients' condition. The BMI correlated with the number of comorbidities as well as the number of hospitalizations for extra-pulmonary causes.
\end{abstract}

Key words: comorbidity, chronic obstructive pulmonary disease, cardiovascular disease, BODE index 


\section{Introduction}

Chronic obstructive pulmonary disease (COPD) is currently recognized as a systemic disease and, as such, it is associated with many systemic disorders and comorbidities. According to the recommendations of the Global Initiative for Obstructive Lung Disease (GOLD) guidelines, the most frequent disorders are cardiovascular diseases (CVDs), body composition disorders, sarcopenia, osteoporosis, depression, and lung cancer. ${ }^{1}$ Additionally, some other concomitant disorders, like asthma-COPD overlap ${ }^{2}$ or obstructive sleep apnea (OSA)COPD overlap syndrome, ${ }^{3}$ are also listed. Mapel et al. showed that only $6 \%$ of the studied patients with COPD had no other chronic medical conditions. The average number of diseases in the COPD cohort was 3.7 vs 1.8 in the control group. ${ }^{4}$ Van Manen et al. reported that over $50 \%$ of 1,145 patients with COPD had more than 1 comorbidity, $15.8 \%$ had between 3 and 4 comorbidities, and $6.8 \%$ had 5 or more comorbid conditions. ${ }^{5}$ The comorbidities influence the frequency and duration of hospitalization $^{6,7}$ and contribute to COPD-related mortality. ${ }^{7}$ In COPD patients, cardiovascular disorders, malignancies and other pulmonary diseases (acute or chronic respiratory failure, cor pulmonale with edema, or pulmonary infections) were responsible for deaths of $14-40 \%, 7-60 \%$, and $4-26 \%$ of the patients, respectively. ${ }^{8}$ This finding was validated by our previous study, in which approx. $12 \%$ of deaths were associated with CVDs. ${ }^{9}$ Comorbidities also affect quality of life, ${ }^{10}$ as well as COPD severity. ${ }^{11}$ Depression, osteoporosis and musculoskeletal alterations are frequently diagnosed in patients with severe COPD. ${ }^{11}$ Frei et al. found that depression, anxiety, peripheral artery disease, cerebrovascular disease, and symptomatic heart disease most strongly affected the patients' health status, and they proposed the use of an index that reflects the impact of comorbidities on the health status of patients with COPD - Comorbidities in Chronic Obstructive Lung Disease (COMCOLD) ${ }^{12}$ It is known that a common risk factor for COPD and some comorbidities is smoking. In the Polish part of the Burden of Obstructive Lung Disease (BOLD) study, the prevalence of COPD increased with exposure to tobacco smoke. ${ }^{13}$
The main aim of our study was to evaluate the prevalence of comorbidities in a cohort of patients with COPD in Poland during 1 year of observation, and to estimate the relationship between the presence of comorbidities and airflow limitation severity and the body mass index, airflow obstruction, dyspnea, and exercise capacity (BODE) index.

\section{Material and methods}

The study is a part of a National Center for Research and Development project called "Chronic obstructive pulmonary disease (COPD) - a systemic disease, the biggest threat of the $21^{\text {st }}$ century" (13 0034 06/2009). Chronic obstructive pulmonary disease was diagnosed according to the GOLD definition. ${ }^{1}$ The study group consisted of 444 consecutive COPD patients (69\% males) at a median age of 66.1 years, with an interquartile range (IQR) of 59.0-74.0, in all stages of disease severity, recruited from the outpatient clinics of the Department of Internal Medicine, Pulmonary Diseases and Allergy, Medical University of Warsaw, Poland, and our partners from Poznań, Gdańsk, Lublin, Wrocław, and Katowice. The median COPD duration was 6.0 years (IQR: 3.0-10.0) and the median number of pack-years was 37.8 (IQR: 25.0-50.0). The inclusion criteria were COPD diagnosis and written informed consent. The patients were evaluated at baseline (V1) and 267 patients were reassessed during a follow-up examination after 12 months (V2). The reasons for the discrepancies between the numbers of subjects in V1 and V2 were death of the patients $(n=40)$, withdrawal of consent $(n=34)$ and being lost to follow-up ( $n=103)$.

The basic characteristics of the investigated group are presented in Table 1.

Chronic obstructive pulmonary disease comorbidities were defined as other diseases coexisting with COPD and affecting the natural history of COPD. ${ }^{1}$ The list of comorbidities for each patient was established during the $1^{\text {st }}$ consultation (V1) based on the detailed analysis of medical documentation, medications used, clinical examination, and laboratory results. Data on the presence of the following comorbidities was analyzed: CVDs (arterial hypertension, coronary heart disease, myocardial infarction, and arrhythmia), cerebrovascular diseases, diabetes, peptic

Table 1. Basic anthropometric data of the investigated group at the $1^{\text {st }}(\mathrm{V} 1)$ and $2^{\text {nd }}(\mathrm{V} 2)$ examination

\begin{tabular}{|c|c|c|c|}
\hline Variables & V1 $(n=444)$ & V2 $(n=267)$ & $\mathrm{p}$-value \\
\hline BMI $\left[\mathrm{kg} / \mathrm{m}^{2}\right]$ & $27.1(23.4-31.2)$ & $27.6(24.0-31.8)$ & 0.46 \\
\hline mMRC & $2.0(1.0-3.0)$ & $2.0(1.0-3.0)$ & 0.43 \\
\hline $\mathrm{FEV}_{1}[\%$ of predicted value] & $50.0(37.4-64.8)$ & $52(39-63)$ & 0.31 \\
\hline $\begin{array}{l}\mathrm{FEV}_{1} \geq 50 \% \text { of predicted value } \\
\mathrm{FEV}_{1}<50 \% \text { of predicted value }\end{array}$ & $\begin{array}{l}221(49.8) \\
223(50.2)\end{array}$ & $\begin{array}{l}142(53.2) \\
125(46.8)\end{array}$ & 0.36 \\
\hline $\begin{array}{l}\text { Number of hospitalizations due to pulmonary } \\
\text { and extra-pulmonary causes }\end{array}$ & $1.0(0-1.0)$ & $0.0(0-1.0)$ & 0.99 \\
\hline
\end{tabular}

Data is presented as median (interquartile range - IQR) or as n (\%); BMI - body mass index; mMRC - modified Medical Research Council scale; FEV 1 - forced expiratory volume in $1 \mathrm{~s}$; COPD - chronic obstructive pulmonary disease; $\mathbf{1} 1$ - the $1^{\text {st }}$ consultation; $\mathrm{V} 2$ - the follow-up consultation. 
ulcers, gastroesophageal reflux disease (GERD), anemia, obstructive sleep apnea (OSA), malignancy (lung and other cancers), bone density abnormalities (osteoporosis and osteopenia), impaired nutritional status, chronic renal disease, and hypothyroidism.

The patients were subjected to the following procedures:

- spirometry with bronchial reversibility testing (Lungtest 1000; MES sp. z o.o., Skawina, Poland) in accordance with the recommendations of the American Thoracic Society/European Respiratory Society (ATS/ERS) ${ }^{15}$;

- a 6-minute walk test (6MWT) in accordance with the ATS recommendations ${ }^{15}$;

- an assessment of dyspnea with the modified Medical Research Council scale (mMRC) ${ }^{16}$;

- the BMI evaluation, calculated as body mass divided by the square of the height (underweight was defined as BMI $<18.5 \mathrm{~kg} / \mathrm{m}^{2}$, healthy weight as $18.5 \leq$ BMI $<25 \mathrm{~kg} / \mathrm{m}^{2}$, overweight as $25 \leq \mathrm{BMI}<30 \mathrm{~kg} / \mathrm{m}^{2}$, and obesity as $B M \geq 30 \mathrm{~kg} / \mathrm{m}^{2}$ );

- the bone mineral density (BMD) assessment within the posterior-anterior lumbar spine (L1-L4) and the femoral neck, performed with dual-energy X-ray absorptiometry (DEXA), using a Discovery Densitometer (Hologic, Waltham, USA) according to the manufacturer's recommended standard procedures (osteopenia was diagnosed for a T-score between -1.0 and -2.5 , osteoporosis for a T-score $\leq-2.5 \mathrm{SD})$;

- laboratory tests (blood count, thyroid stimulating hormone (TSH), serum creatinine concentration, glomerular filtration rate (GFR), and glucose), all performed in the morning after fasting in the central hospital laboratory, using routine methods;

- the BODE index calculation ${ }^{17}$;

- monitoring the number of COPD exacerbations and hospitalizations due to pulmonary and extra-pulmonary causes.

The same procedures were performed at V1 and V2.

For further analyses, the patients were divided into:

- group I (without comorbidities);

- group II (1-2 comorbidities);

- group III (3-5 comorbidities);

- group IV (more than 5 comorbidities).
According to the degree of airflow limitation, measured by forced respiratory volume in $1 \mathrm{~s}\left(\mathrm{FEV}_{1}\right)$, the patients were divided into:

- group 1 (patients with mild and moderate airflow limitation, $\mathrm{FEV}_{1} \geq 50 \%$ of predicted value);

- group 2 (patients with severe and very severe airflow limitation, $\mathrm{FEV}_{1}<50 \%$ of predicted value).

According to GOLD 2017 guidelines, the patients were divided into:

- group A;

- group B;

- group C;

- group D.

\section{Statistical analysis}

Statistical analysis was performed using STATISTICA v. 10 (StatSoft Inc., Tulsa, USA). The Shapiro-Wilk test was used to estimate the normality of the data distribution. The data was presented as mean \pm standard deviation (SD), or as median and interquartile range (IQR), when appropriate. As the majority of the analyzed variables demonstrated a non-normal distribution, the MannWhitney $U$ test and the analysis of variance (ANOVA) Kruskal-Wallis rank test were applied for group comparisons; the correlations were analyzed by the Spearman's rank correlation test. Categorical data was compared by the $X^{2}$ analyses. A p-value $<0.05$ was regarded as statistically significant.

The study was approved by the Bioethical Committee of the Medical University of Warsaw, Poland (KB 207/2008), and all patients gave written informed consent before enrollment in the study.

\section{Results}

No comorbidities were found in 9 patients (2.0\%, group I), 101 patients (22.7\%, group II) had 1-2 comorbidities, 243 (54.7\%, group III) had 3-5 comorbidities, and 91 (20.6\%, group IV) had more than 5 comorbidities. Patients with more comorbidities were older and had higher BMI and

Table 2. Patient characteristics in relation to the number of comorbidities

\begin{tabular}{|c|c|c|c|c|}
\hline Variables & $\begin{array}{c}\text { Group I } \\
n=9\end{array}$ & $\begin{array}{l}\text { Group II } \\
n=110\end{array}$ & $\begin{array}{c}\text { Group III } \\
n=243\end{array}$ & $\begin{array}{c}\text { Group IV } \\
n=91\end{array}$ \\
\hline Age [years] & $59(56-68)^{\#}$ & $62(57-70)^{\Theta_{1}^{* *}}$ & $67(59-75)^{@, \&}$ & $72(63-76)^{\#, * *, \&}$ \\
\hline $\mathrm{BMI}\left[\mathrm{kg} / \mathrm{m}^{2}\right]$ & $24.6(21.2-28.7)$ & $25.1(21.8-29.4)^{@_{*}^{* *}}$ & $27.1(23.7-31.5)^{@}$ & $28.7(24.8-32.4)^{* *}$ \\
\hline $\mathrm{mMRC}$ & $2.0(2.0-2.0)$ & $2.0(1.0-2.0)^{@},^{*}$ & $2.0(1.0-3.0)^{@}$ & $2.0(2.0-3.0)^{*}$ \\
\hline $\mathrm{FEV}_{1}[\%$ of predicted value $]$ & $44.9(26.4-58.2)$ & $53.3(41.7-68.3)^{@}$ & $46.6(35.6-60.4)^{@, \&}$ & $56.0(46.0-68.4)^{8}$ \\
\hline Pack-years of tobacco smoking & $30.0(28.2-40.0)$ & $40.0(29.0-48.0)$ & $36.0(22.0-50.0)$ & $37.5(26.5-50.0)$ \\
\hline COPD duration [years] & $4.0(3.0-10.0)$ & $5.0(2.0-10.0)^{@, *}$ & $7.0(3.0-11.0)^{@}$ & $6.5(3.0-11.0)^{*}$ \\
\hline
\end{tabular}

BMI - body mass index; mMRC - modified Medical Research Council scale; FEV 1 - forced expiratory volume in 1 s; COPD - chronic obstructive pulmonary disease; group I - no comorbidities; group II - 1-2 comorbidities; group III - 3-5 comorbidities; group IV - more than 5 comorbidities; I vs IV: \# p < 0.05; II vs III: ${ }^{@} p<0.05 ;$ II vs IV: * $p<0.05 ;{ }^{* *} p<0.001 ;$ III vs IV: ${ }^{\&} p<0.05$. 
mMRC scores. We did not observe a correlation between the number of comorbidities and COPD airflow limitation severity (Table 2).

The number of comorbidities was related to the BODE index. The BODE index scores for group I vs group II vs group III vs group IV were $1.5 \pm 0.7$ vs $2.6 \pm 2.6$ vs $3.5 \pm 2.5$ vs $2.8 \pm 2.5$, respectively. Differences in the BODE index between groups II and III as well as groups III and IV were statistically significant $(\mathrm{p}=0.002$ and $\mathrm{p}=0.02$, respectively).

Cardiovascular diseases were the most frequent comorbidities. Forty-five patients underwent percutaneous transluminal coronary angioplasty (PTCA) and 9 patients had coronary artery bypass grafting (CABG). We did not find any difference in the number of comorbidities in patients stratified according to the degree of airflow limitation (Table 3).

During V1 we observed significant differences between groups 1 and 2 in the nutritional status. Patients classified as group 1 had higher BMI than patients from group 2 $\left(29.0 \pm 6.1 \mathrm{~kg} / \mathrm{m}^{2}\right.$ vs $\left.26.7 \pm 6.1 \mathrm{~kg} / \mathrm{m}^{2}\right)$. There were 145 patients (33\%) with normal body weight: $28 \%$ of patients in group 1 and $37 \%$ in group 2. Overweight was diagnosed in 32\% of the whole group (32\% and 29\% of patients in groups 1 and 2 , respectively) and obesity was diagnosed in $32 \%$ of the whole group (37\% and $25 \%$ of patients in groups 1 and 2 , respectively). The distribution of nutritional categories in patients with different degrees of bronchial obstruction was significant $(\mathrm{p}<0.001)$. We also found some significant correlations between the number of comorbidities and BMI ( $\mathrm{r}=0.25 ; \mathrm{p}<0.0001)$, and the number of hospitalizations due to extra-pulmonary causes $(\mathrm{r}=0.27$; $\mathrm{p}<0.0001)$.

Bone densitometry was performed in 144 subjects during $\mathrm{V} 1$ and revealed osteopenia and osteoporosis in 66 patients
(45.8\%) and 41 patients (28.5\%), respectively. No differences in the frequency of bone metabolism abnormalities were found between groups 1 and 2 .

We analyzed the number of comorbidities according the GOLD 2017 groups for 373 patients and found differences only for the total number of comorbidities between groups A and $\mathrm{D}(3.7 \pm 1.9$ vs $4.4 \pm 2.0 ; \mathrm{p}=0.017)$.

Two hundred and sixty-seven patients attended the $2^{\text {nd }}$ consultation after 12 months. The most frequently reported new incidents were CVDs: coronary heart disease $(\mathrm{n}=12)$, myocardial infarction $(\mathrm{n}=6)$, arterial hypertension $(n=7)$, arrhythmia $(n=13)$, cerebral stroke $(n=1)$, and transient ischemic attack $(n=2)$. Two new cases of diabetes and 5 new cases of lung cancer were diagnosed.

\section{Discussion}

The present study showed that in a cohort of Polish COPD patients, there was a significant rate of comorbidity. Only $2 \%$ of patients did not report any comorbidities. The greatest was the incidence of CVDs. Cardiovascular diseases were also the most frequently reported newly diagnosed diseases during the 12-month observation. The prevalence of the individual comorbidities did not differ significantly in relation to the degree of airflow limitation, with the exception of cachexia, which was present only in patients with severe and very severe airway obstruction. The correlations between the number of comorbidities and the BODE index suggest that the presence of comorbidities affects the natural history of COPD. Our study contributes to the evaluation of the global burden of COPD and offers an insight into the characteristics of COPD patients in the Polish population.

Table 3. The prevalence of comorbidities in patients with $\mathrm{FEV}_{1} \geq 50 \%$ and $\mathrm{FEV}_{1}<50 \%$ of the predicted value (groups 1 and 2 , respectively)

\begin{tabular}{|c|c|c|c|c|}
\hline Comorbidities & $\begin{array}{l}\text { Whole group }(n=444) \\
n(\%)\end{array}$ & $\begin{array}{c}\mathrm{FEV}_{1} \geq 50 \%(\mathrm{n}=221) \\
n(\%)\end{array}$ & $\begin{array}{c}\mathrm{FEV}_{1}<50 \%(\mathrm{n}=223) \\
\mathrm{n}(\%)\end{array}$ & $p$-value \\
\hline Arterial hypertension & $273(61.5)$ & $144(65.2)$ & $129(57.8)$ & 0.31 \\
\hline $\begin{array}{l}\text { Coronary heart disease/ } \\
\text { myocardial infarction }\end{array}$ & $\begin{array}{l}134(30.1) \\
48(10.8)\end{array}$ & $\begin{array}{l}72(32.6) \\
23(10.4)\end{array}$ & $\begin{array}{l}62(27.8) \\
25(11.2)\end{array}$ & $\begin{array}{l}0.53 \\
0.93\end{array}$ \\
\hline Arrhythmia & $112(25.2)$ & $54(24.4)$ & $58(26.0)$ & 0.92 \\
\hline Diabetes & $85(19.1)$ & $41(18.6)$ & $44(19.7)$ & 0.62 \\
\hline $\begin{array}{l}\text { Cerebrovascular diseases: } \\
\text { cerebral stroke } \\
\text { transient ischemic attacks }\end{array}$ & $\begin{array}{l}16(3.6) \\
6(1.3)\end{array}$ & $\begin{array}{l}9(4.1) \\
4(1.8)\end{array}$ & $\begin{array}{l}7(3.1) \\
2(0.9)\end{array}$ & $\begin{array}{l}0.79 \\
0.27\end{array}$ \\
\hline Peptic ulcers & $96(21.6)$ & $55(24.9)$ & $41(18.4)$ & 0.29 \\
\hline GERD & $81(18.2)$ & $44(19.9)$ & $37(16.6)$ & 0.16 \\
\hline Anemia & $62(14.0)$ & $31(14.0)$ & $31(13.9)$ & 0.34 \\
\hline OSA & $96(21.6)$ & $51(23.1)$ & $45(20.2)$ & 0.64 \\
\hline $\begin{array}{l}\text { Malignancy: } \\
\text { lung cancer } \\
\text { other cancer locations }\end{array}$ & $\begin{array}{l}11(2.5) \\
32(7.2)\end{array}$ & $\begin{array}{l}5(2.3) \\
19(8.6)\end{array}$ & $\begin{array}{c}6(2.7) \\
13(5.8)\end{array}$ & $\begin{array}{l}0.81 \\
0.15\end{array}$ \\
\hline Chronic renal disease & $361(81.3)$ & $172(77.8)$ & $189(84.8)$ & 0.048 \\
\hline Hypothyroidism & $36(8.1)$ & $18(8.1)$ & $18(8.1)$ & 0.63 \\
\hline
\end{tabular}

$\mathrm{FEV}_{1}$ - forced expiratory volume in $1 \mathrm{~s}$; GERD - gastroesophageal reflux disease; OSA - obstructive sleep apnea. 
Our results confirm the observations of other authors. The Rotterdam study showed that the risk of sudden cardiac death is higher in COPD patients. ${ }^{18}$ According to Chatila et al., the frequency of CVDs in COPD patients ranged from 13 to $56 \%$; the frequency of arterial hypertension was as high as $15-82 \% .^{8}$ In our study, arterial hypertension was also the most prevalent CVD. The common risk factors for COPD and CVDs are smoking and systemic inflammation. ${ }^{8}$ However, other researchers do not share this opinion. Sin and Man found that a concomitance of COPD and ischemic heart disease was independent of smoking history, BMI, arterial hypertension, and serum cholesterol concentration; however, these authors found that a decrease of $\mathrm{FEV}_{1}$ by $10 \%$ was associated with a $14 \%$ increase in all-cause mortality, a $28 \%$ increase in mortality due to CVDs and an increase of nonfatal coronary events by almost $20 \%$. The authors concluded that COPD is a powerful, independent risk factor for cardiovascular morbidity and mortality. ${ }^{19}$ The Evaluation of COPD Longitudinally to Identify Predictive Surrogate Endpoints (ECLIPSE) study showed that COPD patients with CVDs reported a worse quality of life, a shorter walking distance in the 6MWT, a higher MRC score, and a higher value of the BODE index. ${ }^{20}$ Our study confirmed that the BODE index values increased with the total number of comorbidities. Nevertheless, the incidence of CVDs did not increase with COPD airflow limitation severity. This finding is in agreement with the report by Lange et al. ${ }^{21}$ However, these authors reported a higher incidence of cerebral stroke in patients at the GOLD 2 stage of severity. In our cohort, the incidence of cerebral stroke was similar in all groups.

We found a relatively high incidence of gastrointestinal diseases in our patients. In the study by Chatila et al., the frequency of gastrointestinal disorders was $15-62 \%{ }^{8}$ Martinez et al. demonstrated that in patients with COPD, GERD had a negative influence on dyspnea severity, quality of life, the incidence of cardiovascular diseases, and the number of COPD exacerbations. ${ }^{22}$ The relationship between GERD and COPD exacerbations has also been reported by other authors.Liang et al. demonstrated that GERD was associated with lung hyperinflation. ${ }^{23}$ However, we could not evaluate this association, as our study protocol did not involve body plethysmography or computed tomography of the chest.

The relationship of diabetes and respiratory diseases has been the subject of research for many years. Hyperglycemia, systemic inflammation and bacterial infection may affect the lung function in patients with diabetes. ${ }^{24,25}$ Literature data shows that COPD is a significant risk factor for type 2 diabetes and that COPD patients with diabetes have a more rapid disease progression and a worse prognosis. ${ }^{26} \mathrm{We}$ did not find a relationship between the prevalence of diabetes and COPD airflow limitation severity. McGhan et al. demonstrated that diabetes increased the risk of re-hospitalization after exacerbation in patients with severe COPD. ${ }^{27}$
The majority of the patients in our cohort were overweight or obese. This could explain the relatively high proportion of patients with OSA (22.3\%). In the study by GreenbergDotan et al., the prevalence of COPD among patients with and without OSA was 7.6 and $3.7 \%$, respectively. ${ }^{28}$ Shiina et al. reported a prevalence of COPD in $12 \%$ of patients with OSA. ${ }^{29}$ This overlap syndrome increased arterial stiffness and cardiovascular risk. ${ }^{30}$ However, we cannot exclude that the high incidence of OSA in our group may be related to a selection bias. All centers that recruited patients have sleep laboratories and outpatient clinics dedicated to the treatment of OSA, to which a larger proportion of patients with OSA/COPD overlap syndrome may be referred.

More than 25\% of the studied subjects reported symptoms from the motor organs; osteoporosis was diagnosed in $16 \%$ of the patients in whom bone densitometry was performed. Chen et al. provided evidence that COPD is an independent risk factor for osteoporosis. ${ }^{30}$ According to the results of McGarvey et al., osteoporosis, along with older age, severely impaired the lung function and a high mMRC score increased the risk of severe exacerbations, requiring hospitalization. ${ }^{31}$

Lung cancer is one of the leading causes of mortality in patients with COPD. ${ }^{9}$ There is evidence that COPD and emphysema are important risk factors for lung cancer. ${ }^{32}$ In our study, $2.6 \%$ of the patients had a history of lung cancer; moreover, 5 new cases were diagnosed over the 12-month observation period. Of note, none of these 5 patients presented with new symptoms and were referred for further diagnostic work-ups upon the detection of focal lesions in a routine chest radiogram.

The incidence of anemia in our patients did not differ significantly from the incidence reported previously by other authors. In a systematic review on the impact of anemia on the course of COPD by Yohannes and Ershler, the incidence of anemia in COPD patients ranged from 7.5 to $34 \% .^{33}$

Chronic renal disease (CRD) is not listed as a typical COPD comorbidity. In our study group, the prevalence of CRD was very high. Our observation confirmed the results of the meta-analysis by Gaddam et al., who demonstrated the increased prevalence of CRD in patients with COPD. ${ }^{34}$

Eight percent of our patients were diagnosed with hypothyroidism. Terzano et al. showed that patients with overt hypothyroidism had lower $\mathrm{PaO} 2$, and maximal inspiratory and expiratory pressure compared with subjects with subclinical hypothyroidism and the control group. ${ }^{35}$

The data on comorbidities in our patients came mainly from a detailed questionnaire and medical documentation, but were not verified with diagnostic tests. This is the major limitation of our study. However, we made every effort to exclude a potential overdiagnosis and we carefully analyzed the available medical documentation of the patients. Another limitation of our study is the number of patients who attended the follow-up consultation: they 
accounted for only $60 \%$ of the initial study group. Finally, as the patients were recruited only in university hospitals, we cannot exclude a selection bias, which may have influenced the results of the study.

We conclude that in a cohort of Polish COPD patients, the presence of comorbidities is frequent in all stages of the disease. The most frequent comorbidities were CVDs. This is in agreement with other studies from different regions. The correlation between the number of comorbidities and the BODE index confirms the negative impact of the comorbidities on the course of COPD and is irrespective of airflow limitation severity.

\section{References}

1. From the Global Strategy for the Diagnosis, Management and Prevention of COPD, Global Initiative for Chronic Obstructive Lung Disease (GOLD) 2017. Available from: https://goldcopd.org. Accessed January 31, 2017.

2. Alshabanal A, Zafari Z, Albanyan O, et al. Asthma and COPD Overlap Syndrome (ACOS): A systematic review and meta analysis. PLOSONE. 2015;10:e0136065.

3. Soler X, Gaio E, Powell FL, et al. High prevalence of obstructive sleep apnea in patients with moderate to severe COPD. Ann Am Thorac Soc. 2015;12:1219-1225.

4. Mapel DW, Hurley JS, Frost FJ, et al. Health care utilization in chronic obstructive pulmonary disease: A case-control study in a health maintenance organization. Arch Intern Med. 2000;160:2653-2658.

5. van Manen JG, Bindels PJ, IJzermans CJ, et al. Prevalence of comorbidity in patients with a chronic airway obstruction and controls over the age of 40. J Clin Epidemiol. 2001;54:287-293.

6. Kinnunen $T$, Säynäjäkangas $O$, Tuuponen T, et al. Impact of comorbidities on the duration of COPD patients' hospital episodes. Respir Med. 2003;97:143-146.

7. Terzano C, Conti V, Di Stefano F, et al. Comorbidity, hospitalization, and mortality in COPD: Results from a longitudinal study. Lung. 2010; 188:321-329.

8. Chatila WM, Thomashow BM, Minai OA, et al. Comorbidities in chronic obstructive pulmonary disease. Proc Am Thorac Soc. 2008;5:549-555.

9. Rubinsztajn, R. Chazan R. Mortality and comorbidity in hospitalized chronic obstructive pulmonary disease patients. PneumonolAlergol Pol. 2011;79:343-346.

10. Koskela J, Kilpeläinen $\mathrm{M}$, Kupiainen $\mathrm{H}$, et al. Co-morbidities are the key nominator of the health-related quality of life in mild and moderate COPD. BMCPulm Med. 2014;14:102. doi: 10.1186/1471-2466-14-102

11. Sundh J, Johansson G, Larsson K, et al. Comorbidity and health-related quality of life in patients with severe chronic obstructive pulmonary disease attending Swedish secondary care units. Int J Chron Obstruct Pulmon Dis. 2015;10:173-183.

12. Frei $A$, Muggensturm $P$, Putcha $N$, et al. Five comorbidities reflected the health status in patients with chronic obstructive pulmonary disease: The newly developed COMCOLD index. J Clin Epidemiol. 2014;67:904-911.

13. Niżankowska-Mogilnicka E, Mejza F, Biust AS, et al. Prevalence of COPD and tobacco smoking in Małopolska region - results from the BOLD study in Poland. Pol Arch Med Wewn. 2007;117:402-410.

14. Miller MR, Hankinson J, Brusasco V, et al.; ATS/ERS Task Force. Standardisation of spirometry. Eur Respir J. 2005;26:319-338.
15. ATS Committee on Proficiency Standards for Clinical Pulmonary Function Laboratories. ATS statement: Guidelines for the six-minute walk test. Am J Respir Crit Care Med. 2002;166:111-117.

16. Mahler DA, Wells CK. Evaluation of clinical methods for rating dyspnea. Chest. 1988;93:580-586.

17. Celli BR, Cote CG, Marin JM, et al. The body-mass index, airflow obstruction, dyspnea, and exercise capacity index in chronic obstructive pulmonary disease. N Engl J Med. 2004;350:1005-1012.

18. Lahousse L, Niemeijer MN, van den Berg ME, et al. Chronic obstructive pulmonary disease and sudden cardiac death: The Rotterdam study. Eur Heart J. 2015;36:1754-1761.

19. Sin DD, Man MF. Chronic obstructive pulmonary disease as a risk factor for cardiovascular morbidity and mortality. Proc Am Thorac Soc. 2005;2:8-11.

20. Miller J, Edwards LD, Agustí A, et al. Comorbidity, systemic inflammation and outcomes in the ECLIPSE cohort. Respir Med. 2013;107: 376-384.

21. Lange $\mathrm{P}$, Mogelvang $\mathrm{R}$, Marott $\mathrm{J}$, et al. Cardiovascular morbidity in COPD: A study of the general population. COPD. 2010;7:5-10.

22. Martinez $\mathrm{CH}$, Okajima Y, Murray S, et al. Impact of self-reported gastroesophageal reflux disease in subjects from COPD gene cohort. Respir Res. 2014;15:62. doi: 10.1186/1465-9921-15-62

23. Liang $B$, Wang $M, Y i Q$, et al. Association of gastroesophageal reflux disease risk with exacerbations of chronic obstructive pulmonary disease. Dis Esophagus. 2013;26:557-560.

24. Shah $\mathrm{SH}$, Sonawane $\mathrm{P}, \mathrm{Nahar} \mathrm{P}$, et al. Pulmonary function tests in type 2 diabetes mellitus and their association with glycemic control and duration of the disease. Lung India. 2013;30:108-112.

25. Aparna A. Pulmonary function tests in type 2 diabetics and nondiabetic people - a comparative study. J Clin Diagn Res. 2013;7: 1606-1608.

26. Gläser S, Krüger S, Merkel M, Bramlage P, Herth FJ. Chronic obstructive pulmonary disease and diabetes mellitus: A systematic review of the literature. Respiration. 2015;89:253-264.

27. McGhan R, Radcliff $T$, Fish R, et al. Predictors of rehospitalization and death after a severe exacerbation of COPD. Chest. 2007;132: 1748-1755.

28. Greenberg-Dotan S, Reuveni $\mathrm{H}$, Tal A, et al. Increased prevalence of obstructive lung disease in patients with obstructive sleep apnea. Sleep Breath. 2014;18:69-75.

29. Shiina K, Tomiyama H, Takata $Y$, et al. Overlap syndrome: Additive effects of COPD on the cardiovascular damages in patients with OSA. Respir Med. 2012;106:1335-1341.

30. Chen SJ, Liao WC, Huang KH, et al. Chronic obstructive pulmonary disease and allied conditions is a strong independent risk factor for osteoporosis and pathologic fractures: A population-based cohort study. QJM. 2015;108:633-640.

31. McGarvey L, Lee AJ, Roberts J, et al. Characterisation of the frequent exacerbator phenotype in COPD patients in a large UK primary care population. Respir Med. 2015;109:228-237.

32. Sanchez-Salcedo P, Berto J, de-Torres JP, et al. Lung cancer screening: Fourteen-year experience of the Pamplona early detection program (P-IELCAP). Arch Bronconeumol. 2015;51:169-176.

33. Yohannes AM, Ershler WB. Anemia in COPD: A systematic review of the prevalence, quality of life, and mortality. Respir Care. 2011;56:644-652.

34. Gaddam S, Gunukula SK, Lohr JW, et al. Prevalence of chronic kidney disease in patients with chronic obstructive pulmonary disease: A systematic review and meta-analysis. BMC Pulm Med. 2016;16:158. doi: 10.1186/s12890-016-0315-0

35. Terzano C, Romani S, Paone G, et al. COPD and thyroid dysfunctions. Lung. 2014;192:103-109. 